\title{
The Oxidation of Tricarboxylic Acid Cycle Intermediates by a Strain of Corynebacterium erythrogenes
}

\author{
BY R. G. TUCKER \\ Microbiology Unit, Department of Biochemistry, University of Oxford
}

(Received 25 March 1960)

\begin{abstract}
SUMMARY
Washed suspensions of Corynebacterium erythrogenes strain 142, grown on a yeast extract medium, were unable to oxidize some members of the tricarboxylic acid cycle immediately unless these compounds had been added to the growth medium. At $25^{\circ}$ the organism eventually acquired the ability to oxidize these compounds; with succinate rapid oxidation was not obtained even after $6 \mathrm{hr}$. Rapid oxidation of succinate did occur when washed suspensions were incubated first with L- or D-malate. The lag periods were shortened by the addition of ammonium sulphate, but adaptation was prevented by chloramphenicol, 2:4-dinitrophenol, azide or an increase in temperature to $37^{\circ}$. Neither chloramphenicol nor the increase in temperature affected oxidation by adapted organisms; 2:4-dinitrophenol and azide were inhibitory, especially when added with the substrate. Extracts of unadapted organisms oxidized immediately all those compounds which intact organisms did not. Chloramphenicol and the respiratory uncoupling agents did not inhibit oxidations by the cell extracts. Extracts from adapted or unadapted bacteria reacted with succinate, malate and fumarate in the presence of hydroxylamine to form substances which gave coloured compounds with ferric chloride. The compounds with fumarate and malate were not identified. These compounds and succinhydroxamate were formed equally well by extracts of organisms grown in the absence or presence of the dicarboxylic acids. There was no evidence that the enzymes responsible for these reactions are directly concerned with the penetration of the acids into $C$. erythrogenes.
\end{abstract}

\section{INTRODUCTION}

Some micro-organisms either do not readily oxidize certain intermediates of the tricarboxylic acid (TCA) cycle (Krebs, Gurin \& Eggleston, 1952; Moses, 1955; Davis, 1956) or will only do so after a lag period (Karlsson \& Barker, 1948; Barrett, Larsen \& Kallio, 1953; Kogut \& Podoski, 1953). The accepted explanation of the phenomenon is that access of the added substrates to the enzymes is prevented by impermeability, which in some micro-organisms can be overcome by inducible transport processes (Kogut \& Podoski, 1953; Clarke \& Meadow, 1959). During an investigation of the metabolism of Corynebacterium erythrogenes lag periods before the oxidation of various tricarboxylic acid cycle intermediates were observed. The properties of intact organisms and of extracts have now been examined to see whether these results can similarly be ascribed to permeability barriers. 


\section{METHODS}

\section{Organism and growth of cultures}

Corynebacterium erythrogenes strain 142 was originally isolated from cod skin by Dr J. M. Shewan (Department of Scientific and Industrial Research, Torry Research Station, Aberdeen). Its morphology and general growth characteristics resemble those of two other yellow-pigmented, porphyrin-excreting, coryneform organisms obtained from cod skin slime (Hodgkiss, Liston, Goodwin \& Jamikorn, 1954). The organism was maintained by monthly subculture on to slopes of tryptic meat agar.

The basal growth medium used in the experiments to be described contained (g./l.): $\mathrm{Na}_{2} \mathrm{HPO}_{4} .12 \mathrm{H}_{2} \mathrm{O}, 16 ; \mathrm{KH}_{2} \mathrm{PO}_{4}, 1.3 ; \mathrm{NaCl}, 8 \cdot 5 ; \mathrm{MgSO}_{4} .7 \mathrm{H}_{2} \mathrm{O}, 0 \cdot 12$; yeast extract (Difco), 5.0; glucose, 18. The solution was made up without glucose, adjusted to $\mathrm{pH} 7 \cdot 6$ with $\mathrm{N}-\mathrm{NaOH}$ and sterilized by autoclaving $\left(10 \mathrm{~min}\right.$. at $\left.115^{\circ}\right)$. Glucose was then added as a separately autoclaved solution. Organic acids were added to this medium (containing glucose) as autoclaved solutions of their sodium salts, usually to a final concentration of $0 \cdot 1 \mathrm{M}$.

Growth from a fresh $24 \mathrm{hr}$. tryptic meat agar slope culture was diluted in water to give organisms equivalent to $c .6 \mu \mathrm{g}$. dry wt. $/ \mathrm{ml}$. This suspension ( $1.0 \mathrm{ml}$.) was used to inoculate $40 \mathrm{ml}$. basal medium contained in 1 -shaped tubes (Monod, Cohen-Bazire \& Cohn, 1951) of $120 \mathrm{ml}$. capacity. The tubes were incubated in a water bath at $25^{\circ}$ and aerated by rocking at 36 oscillations/min. by a device similar to that of van Heyningen \& Gladstone (1953).

Larger volumes of culture (up to 1 l.) were grown in $5 \mathrm{l}$. rotating flasks in an apparatus similar to that described by Mitchell (1949), in which the temperature could be controlled by having the flasks immersed in water at $25^{\circ}$.

All cultures were harvested towards the end of exponential growth (40 hr.) and washed twice with the culture volume of $0.073 \mathrm{M}-\mathrm{NaCl}$.

\section{Preparation of cell-free extracts}

Ultrasonic preparations. Freshly harvested washed bacteria were resuspended in 0.05 $\mathrm{M}$-phosphate buffer $(\mathrm{pH} \mathrm{7.0)}$ ) at a concentration equiv. 30-40 mg. dry wt. organism $/ \mathrm{ml}$. Volumes of about $15 \mathrm{ml}$. were subjected to ultrasonic vibration at $25 \mathrm{kc}$./sec. for $5 \mathrm{~min}$. (Mullard Ultrasonic Generator, Type E 7590 B: Mullard Ltd, London). The transducer assembly was cooled by a stream of cold tap water. Unbroken organisms and coarse debris were removed by centrifuging at $25,000 \mathrm{~g}$ for $10 \mathrm{~min}$. For some experiments the preparation was dialysed against 50 vol. of cold 0.05 M-phosphate buffer ( $\mathrm{pH} \mathrm{7 \cdot 0)}$ for $20 \mathrm{hr}$.

Fractions from lysozyme-treated organisms. Washed organisms (equiv. c. 1 g. dry wt.) were suspended in $144 \mathrm{ml}$. of a mixture consisting of $0.03 \mathrm{M}$-phosphate buffer $(\mathrm{pH} \mathrm{7 \cdot 0)}+0.04 \mathrm{M}-\mathrm{NaCl}+\mathrm{M}$-sucrose. To this lysozyme (Armour Laboratories Ltd, Hampden Park, Eastbourne, Sussex) was added to a final concentration of $200 \mu \mathrm{g}$./ $\mathrm{ml}$. The suspension was incubated at $25^{\circ}$ for $3 \mathrm{hr}$. with occasional shaking by hand, and then centrifuged at $1500 \mathrm{~g}$ for $30 \mathrm{~min}$. After washing in an equal volume of the above solution without lysozyme, the organisms were sedimented by centrifugation and lysed by resuspension in $100 \mathrm{ml}$. 0.05 $\mathrm{M}$-phosphate buffer ( $\mathrm{pH} \mathrm{7.0)}$. The lysate was mixed thoroughly by squirting through a pipette, and after about $10 \mathrm{~min}$. 


\section{Oxidation by C. erythrogenes}

at room temperature was centrifuged at $25,000 \mathrm{~g}$ for $30 \mathrm{~min}$. to yield a clear viscous supernatant fluid and a yellow pellet. The pellet was washed twice with a mixture of $0.07 \mathrm{M}-\mathrm{NaCl}+0.05 \mathrm{M}$-phosphate buffer $(\mathrm{pH} \mathrm{7.0)}$ ) and finally suspended in $0.05 \mathrm{M}$ phosphate buffer ( $\mathrm{pH} 7 \cdot 0)$.

For some manometric experiments, lysozyme ( $0 \cdot 1 \mathrm{ml}$. aqueous solution containing $2 \mathrm{mg} . / \mathrm{ml}$.) was added directly to suspensions of organisms in the presence or in the absence of $\mathbf{M}$-sucrose in manometer vessels.

\section{Estimations and reagents}

Manometric methods. Oxygen uptake was measured in Warburg manometers with air as the gas phase. Enzyme preparation or washed suspension (equiv. c. 5-10 mg. dry wt. organism $/ 2 \mathrm{ml}$. mixture of $0.07 \mathrm{M}-\mathrm{NaCl}+0.05 \mathrm{M}$-phosphate buffer, $\mathrm{pH} \mathrm{7 \cdot 0)}$ was placed in the main compartment. The substrate was in the side bulb and the centre well contained $0.2 \mathrm{ml} .20 \%$ (w/v) KOH. Distilled water and any other additions were made to bring the total volume to $3 \mathrm{ml}$. Rates of $\mathrm{O}_{2}$ uptake $\left(Q_{\mathrm{O}_{2}}\right)$ were expressed as $\mu \mathrm{l}$./mg. dry wt. organism/hr.

Oxalacetic decarboxylase was measured by the method of Herbert (1955).

Hydroxamate formation. The incubation mixture contained: enzymic extract; tris buffer (2-amino-2-hydroxymethylpropane-1:3 diol), $\mathrm{pH} \mathbf{7 \cdot 4}, 20 \mu \mathrm{mole} ; \mathrm{MgCl}_{2}$, $10 \mu$ mole; cysteine, $6 \mu$ mole; coenzyme A (CoA), $0.05 \mu$ mole; adenosine triphosphate (ATP), $10 \mu$ mole; hydroxylamine (hydroxylamine hydrochloride adjusted to $\mathrm{pH} \mathrm{7.0}$ with $\mathrm{KOH}$ ), $800 \mu$ mole; substrate, water to $2 \mathrm{ml}$.; in $1.5 \times 11 \mathrm{~cm}$. centrifuge tubes. After $2 \mathrm{hr}$. incubation at $30^{\circ}, 1 \mathrm{ml}$. ferric chloride reagent (Berg, 1956) was added, and after centrifugation to remove precipitate the optical density at $540 \mathrm{~m} \mu$ was measured in the Unicam SP. 600 spectrophotometer (Unicam Instruments Ltd, Cambridge), using cuvettes of $1 \mathrm{~cm}$. light path.

Keto acids. Total keto acids were estimated by the method of Friedemann \& Haugen (1943). For chromatographic identification the 2:4-dinitrophenyl-hydrazones were extracted into ethyl acetate and ascending chromatograms were developed in the solvent of Dagley, Fewster \& Happold (1952) on Whatman no. 1 paper.

Protein. This was measured by the method of Lowry, Rosebrough, Farr \& Randall (1951), with crystalline bovine plasma albumen (Armour Laboratories, Ltd, Hampden Park, Eastbourne, Sussex) as the standard.

Dry weight of washed suspensions. An EEL (Evans Electroselenium Ltd, Halstead, Essex) photoelectric colorimeter with a neutral density filter was used to assess the turbidity of washed suspensions. The instrument was calibrated by relating readings to the turbjdities of washed suspensions of known dry wt. organism/ml.

Reagents. Analar grade or recrystallized chemicals were used whenever possible. Special materials were obtained from the following sources: coenzyme A (CoA, 70-75\% pure), triphosphopyridine nucleotide (TPN), diphosphopyridine nucleotide (DPN) and adenosine triphosphate (ATP) from the Sigma Chemical Co., St Louis, Mo., U.S.A.; chloramphenicol from Parke, Davis and Co., Hounslow, Middlesex.

\section{RESULTS}

\section{Oxidation of intermediates by washed suspensions}

Washed suspensions of Corynebacterium erythrogenes harvested after growth for $40 \mathrm{hr}$. in the basal medium were tested for their ability to oxidize members of the 


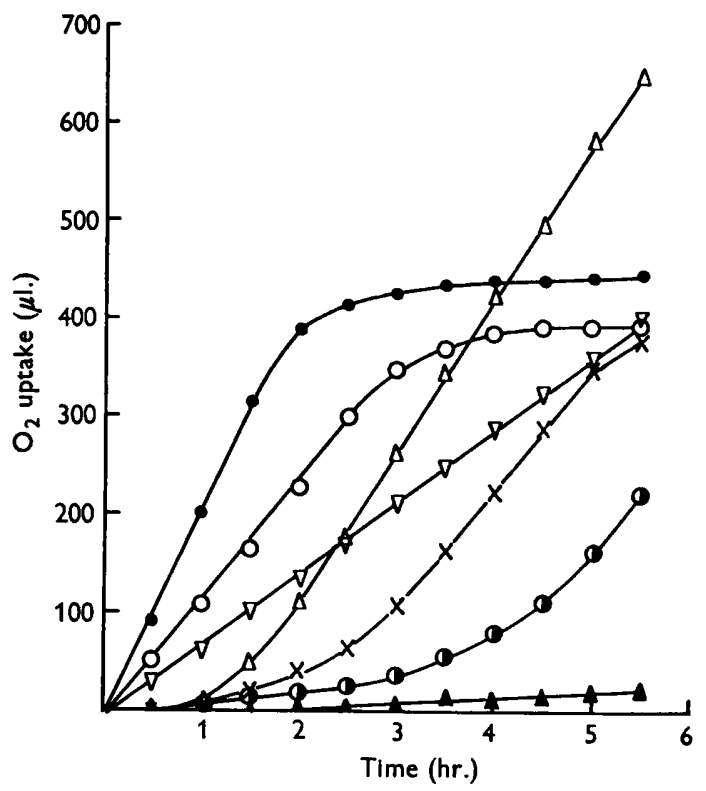

Fig. 1. Oxidative ability of Corynebacterium erythrogenes grown on the basal medium alone. Substrates (10 $\mu$ mole), $\Delta-\Delta$, succinate; $\circlearrowleft-O$, fumarate; $\times-\times$, L-malate; $\nabla-\nabla, \alpha$-oxoglutarate; $\Delta-\Delta$, citrate; $\bigcirc-0$, acetate; -0 , pyruvate. Temperature $25^{\circ}$. Endogenous $\mathrm{O}_{2}$ uptake has been subtracted.

tricarboxylic acid cycle and related compounds. With acetate, pyruvate and $\alpha$-oxoglutarate, the rates of $\mathrm{O}_{2}$ uptake were linear from the time of substrate addition; with citrate, malate and fumarate, there was a lag before rapid rates of oxidation were obtained; with succinate there was only a slight uptake of oxygen even after $6 \mathrm{hr}$. (Fig. 1). The lag period with a particular intermediate could be abolished by incorporating it in the growth medium, and the patterns of oxidation obtained under these conditions are shown in Table 1.

Table 1. Oxidative ability of washed suspensions of Corynebacterium erythrogenes grown on the basal medium with various supplements

The values have been corrected for the oxygen uptakes in the absence of substrate. Temperature $25^{\circ}$.

Substrates added to the basal growth medium

\begin{tabular}{|c|c|c|c|c|c|c|c|}
\hline Cibctrote & \multicolumn{6}{|c|}{$Q_{\mathrm{O}_{2}}$ values } & $\begin{array}{l}\alpha \text {-Oxo- } \\
\text { glutarat }\end{array}$ \\
\hline Pyruvate & $\mathbf{3 0}$ & - & 47 & 28 & 25 & - & 48 \\
\hline Acetate & $16 \cdot 6$ & $\mathbf{3 1} \cdot \mathbf{5}$ & 一 & - & - & - & 一 \\
\hline Succinate & $(*)$ & $(*)$ & $19 \cdot 5$ & 35 & 28 & $(*)$ & $(*)$ \\
\hline L-Malate & $(\mathbf{1 8 \cdot 8 )}$ & (19) & $17 \cdot 2$ & 29 & 26 & (*) & $(*)$ \\
\hline Fumarate & (18) & $(18 \cdot 4)$ & 17 & 30 & 25 & $(*)$ & $(*)$ \\
\hline Citrate & 24 & 19 & 30 & 24 & 13 & 61 & (18) \\
\hline$\alpha$-Oxoglutarate & 11 & $19 \cdot 2$ & $7 \cdot 8$ & $\mathbf{3} \cdot \mathbf{2}$ & $5 \cdot 3$ & 42 & 43.5 \\
\hline None & $5 \cdot 8$ & $7 \cdot 4$ & 6 & 18 & $6 \cdot 4$ & $8 \cdot 7$ & $6 \cdot 4$ \\
\hline
\end{tabular}

( ) Indicates lag period; (*) indicates the linear rate was not achieved after $5 \mathrm{hr}$. ; — indicates not tested. 


\section{Factors affecting the lag period}

The inability of organisms grown on the basal medium to oxidize malate, fumarate, succinate and citrate without a lag suggested that induced enzyme formation was required before these substrates could be metabolized. The effect of various treatments known to affect induced enzyme formation was therefore investigated.

Chloramphenicol. Chloramphenicol, $20 \mu \mathrm{g}$. $/ \mathrm{ml}$., completely prevented the increase in the rates of oxidation normally shown by organisms grown in the basal medium; the oxidation of compounds by bacteria grown in their presence was unaffected.
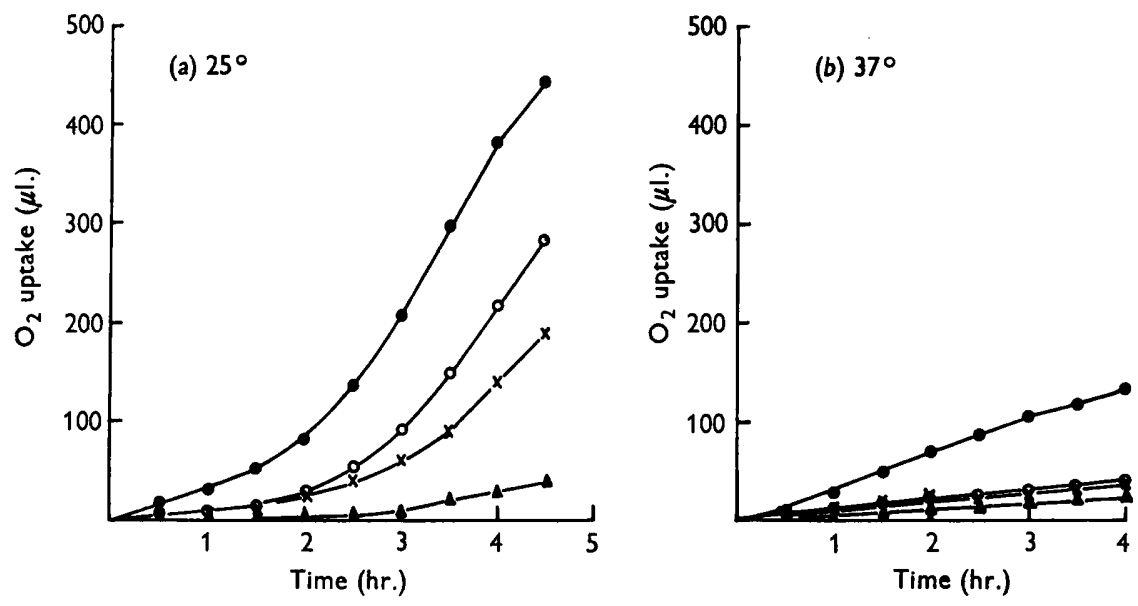

Fig. $2 a, b$. Effect of temperature on the adaptation of washed suspensions of Corynebacterium erythrogenes to tricarboxylic acid cycle intermediates. Substrates (10 $\mu$ mole), $\longrightarrow$, citrate; $\mathrm{O}-\mathrm{O}$, L-malate; $\times-\times$, fumarate; $\Delta-\Delta$, succinate. Temperature (a) $25^{\circ}$ and (b) $37^{\circ}$. Endogenous $\mathrm{O}_{2}$ uptakes have been subtracted.

Temperature. The growth of Corynebacterium erythrogenes is inhibited at temperatures greater than $\mathbf{2 5}^{\circ}$; the effect of higher temperatures on the adaptive response was therefore examined. At $37^{\circ}$, malate, fumarate, succinate and citrate were oxidized by organisms grown on the basal medium alone, but the rates of oxidation were slow and did not show the increase with time which was characteristic of suspensions incubated at $25^{\circ}$ (Fig. 2). The increase in temperature was not directly inhibitory to oxidation; for example, in one experiment with organisms grown in the presence of malate the $Q_{\mathrm{O}_{2}}$ for malate was increased from 25 to 51 on raising the temperature from $25^{\circ}$ to $37^{\circ}$.

2:4-Dinitrophenol and sodium azide. The adaptive response was completely abolished by 2:4-dinitrophenol (DNP; at $0.00036 \mathrm{M})$ and azide $(0.0036 \mathrm{M})$. These inhibitors also interfered with the utilization of substrates by adapted organisms (Table 2), and higher concentrations of DNP (0.0018 M) suppressed malate oxidation entirely. This effect of DNP and azide on adapted organisms was most marked when substrate and inhibitor were added together; much less slowing of the rate of oxidation was produced if the inhibitor was added some time after the substrate.

Added nitrogen and energy sources. The long time-lag before washed suspensions began to oxidize malate and fumarate at a rapid rate suggested that some factor 
Table 2. Effect of 2:4-dinitrophenol and azide on the rates of oxidation by fumarate-grown Corynebacterium erythrogenes

Standard manometric conditions with substrates (10 $\mu$ mole) added from side arm. Temperature $25^{\circ}$.

$\begin{array}{lrcr}\text { Substrate } & \begin{array}{c}\text { No } \\ \text { inhibitor }\end{array} & \begin{array}{c}\text { Azide } \\ (0 \cdot 0036 \mathrm{M}) \\ \mathrm{O}_{2} \text { uptake }(\mu \mathrm{l} . / \mathrm{hr} .)\end{array} & \begin{array}{c}\text { 2:4-Dinitrophenol } \\ (0 \cdot 00036 \mathrm{M})\end{array} \\ \text { None } & \overbrace{\text { Succinate }}^{43} & 46 & 72 \\ \text { L-Malate } & 213 & 106 & 122 \\ \text { Fumarate } & 183 & 96 & 92 \\ & 188 & 86 & 107\end{array}$

connected with protein synthesis might be limiting. The large internal store of amino acids which Gram-positive micro-organisms contain is usually sufficient for induced enzyme formation, though Spiegelman \& Dunn (1947) found that the process may be speeded in the presence of an external source of nitrogenous compounds. With Corynebacterium erythrogenes the addition of $100 \mu$ mole ammonium sulphate to washed suspensions under the standard manometric conditions lessened the time required for the achievement of linear rates of oxidation of malate and fumarate, though not of citrate. With succinate there was a slight increase in the rate of oxidation after about $6 \mathrm{hr}$.

The availability of energy may have a marked effect on the kinetics of induced enzyme synthesis (see Monod, Pappenheimer \& Cohen-Bazire, 1952), and Clarke \& Meadow (1959) found that the formation of the citrate transport mechanism in Pseudomonas aeruginosa was more rapid when a small amount of fumarate was added so that the organisms were not solely dependent on citrate for energy supply. The addition of a number of readily oxidizable substrates to washed suspensions of Corynebacterium erythrogenes did not diminish the lag periods with citrate, malate, fumarate or succinate. Glucose, which has an inhibitory action on the formation of some induced enzymes (Neidhardt \& Magasanik, 1957), including the transport mechanism required for citrate utilization by Aerobacter aerogenes (Davis, 1956), had no effect on the adaptation processes of $C$. erythrogenes.

The effect of adaptation to other substrates. Growth in the presence of L-malate or fumarate or succinate yielded organisms capable of oxidizing all three substances without a lag (Table 1). The possibility was examined that the long time lag shown towards succinate by washed suspensions which had been grown in the basal medium alone might be influenced by the adaptation of the harvested organisms to malate or fumarate. Bacteria were adapted to a small amount of L-malate $(2.5 \mu \mathrm{mole})$ in manometer vessels and after $4 \mathrm{hr}$., when the $\mathrm{O}_{2}$ uptake with this substrate had ceased, $10 \mu$ mole succinate were added, with or without chloramphenicol, from the second side arm (Fig. 3). The immediate rapid oxidation of succinate which occurred was unaffected by the presence of chloramphenicol, and is to be contrasted with the slow rate of $\mathrm{O}_{2}$ uptake in the control after incubation for $6 \mathrm{hr}$. with succinate. In other experiments it was found that incubation of washed suspensions with $\mathrm{D}$-malate for $3 \mathrm{hr}$. enabled the immediate rapid oxidation of L-malate, fumarate and succinate. 


\section{Oxidation of intermediates by cell-free extracts}

If, as with other organisms, the inability of Corynebacterium erythrogenes to oxidize TCA cycle intermediates rapidly is due to a permeability barrier which is overcome during the period of adaptation, cell-free preparations should have a wider range of oxidative activity than intact organisms.

Ultrasonic preparations. Malate, fumarate and citrate were all oxidized rapidly from the time of addition by ultrasonic preparations of organisms grown on the basal medium alone (Table 3). Disruption of the bacteria, however, caused a loss of the ability to oxidize $\alpha$-oxoglutarate, and attempts to demonstrate $\alpha$-oxoglutarate dehydrogenase in these ultrasonic preparations by the method of Kaufman (1955) were unsuccessful. Succinate was oxidized only slowly by ultrasonic preparations, though definite succinic dehydrogenase activity was shown by using phenazine methosulphate as hydrogen acceptor (Singer \& Kearney, 1957).

Table 3. Oxidation of some tricarboxylic acid cycle intermediates by ultrasonic extracts of Corynebacterium erythrogenes grown on the basal medium alone

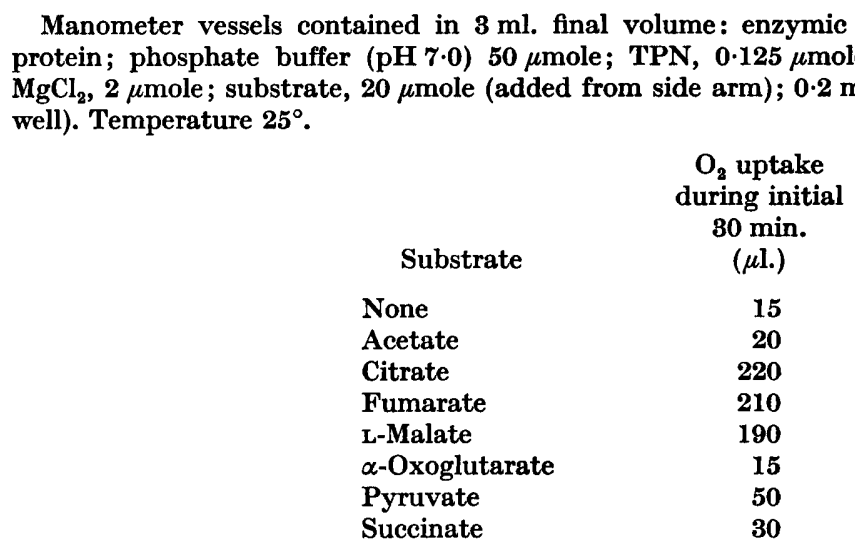

Lysozyme-treated organisms. During an investigation into various methods of disrupting the organism it was found that its potential oxidative ability when grown on the basal medium alone could be shown by treatment with lysozyme. Organisms treated with lysozyme in the absence of sucrose oxidized malate and fumarate at an initial rate which was the same as that of equivalent suspensions of intact bacteria grown in the presence of these compounds; however, after the consumption of about 1 atom $\mathrm{O}_{2}$ /mole substrate the rate became slower. Citrate was oxidized at the latter rate from the time of tipping, though faster oxidation could be obtained by the addition of DPN (0.14 $\mu$ mole) and TPN (0.125 $\mu$ mole). The lyzozyme-treated suspensions oxidized succinate and $\alpha$-oxoglutarate very slowly. Examination of the contents of the manometer vessels at the end of the experiment revealed pyruvate and oxaloacetate as the products of the oxidation of both malate and fumarate, and the formation of $\alpha$-oxoglutarate from citrate.

Organisms treated with lysozyme in the presence of $M$-sucrose showed an adaptive type of response with malate, fumarate and citrate. As with intact organisms the 
adaptation was prevented by chloramphenicol, which had no effect on the oxidation of substrates by bacteria treated with lysozyme in the absence of sucrose (Fig. 4).

On centrifugation at $25,000 \mathrm{~g}$ for $30 \mathrm{~min}$., suspensions of Corynebacterium erythrogenes which had been treated with lysozyme in the presence of $\mathrm{M}$-sucrose and subsequently lysed separated into a clear viscous supernatant fluid and a yellow pellet. The pellet was washed twice in a mixture of $0.07 \mathrm{M}-\mathrm{NaCl}+0.05 \mathrm{M}-$ phosphate

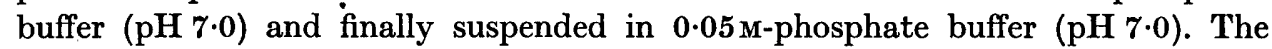
supernatant fluid and pellet fractions were tested for various enzymic activities.

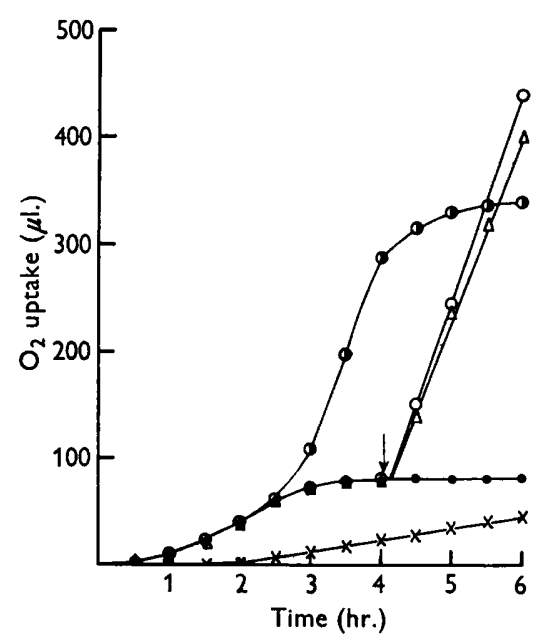

Fig. 3

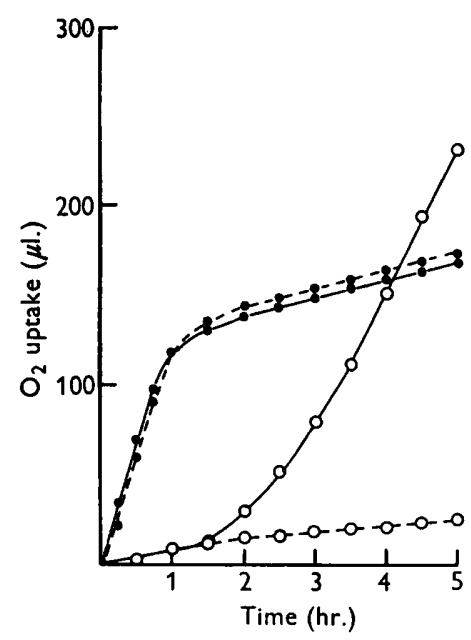

Fig. 4

Fig. 3. Effect of adaptation of washed suspensions of Corynebacterium erythrogenes to malate on the rate of oxidation of succinate. Substrates, $\square-1$, L-malate (10 $\mu$ mole); - L-malate (2.5 $\mu$ mole); $\times-\times$, succinate $(10 \mu \mathrm{mole})$ added at zero time. Addition of succinate $(10 \mu \mathrm{mole})$, with, $\mathrm{O}-\mathrm{O}$ or without, $\Delta-\Delta$, chloramphenicol $(20 \mu \mathrm{g} / \mathrm{ml}$.) at point shown by arrow after the completion of oxidation of $2.5 \mu$ mole L-malate. Temperature $25^{\circ}$. Endogenous $\mathrm{O}_{2}$ uptakes have been subtracted.

Fig. 4. Effect of chloramphenicol and the oxidation of fumarate by suspensions of Corynebacterium erythrogenes treated with lysozyme in the presence or absence of sucrose. Standard manometric conditions with lysozyme $(200 \mu \mathrm{g}$.) in each vessel and fumarate $(10 \mu$ mole) added from side arm. Sucrose $(M)$ present, $\bigcirc$; absent, $\odot$. Chloramphenicol $\left(20 \mu \mathrm{g} . / \mathrm{ml}\right.$.) present, - - - ; absent, _- Temperature $25^{\circ}$. Endogenous $\mathrm{O}_{2}$ uptakes have been subtracted.

The pellet contained all the malate oxidizing activity of the whole lysate, while all the oxaloacetic decarboxylase was located in the supernatant fluid. A similar distribution of malic dehydrogenase was indicated by using ferricyanide as hydrogen acceptor (Cohn, 1956), showing that localization of the cytochrome system in the pellet was not responsible for these results. Comparison of the two fractions obtained from organisms grown in the basal medium alone or with added fumarate revealed no marked difference in the activities, in terms of protein content, of malic dehydrogenase and oxalacetic decarboxylase. The pellet fraction alone was unable to oxidize fumarate as fast as the whole lysate. However, this rate could be attained by adding the supernatant fluid, showing that fumarase was present in both fractions. 
The distribution of cytochromes between the supernatant fluid and the pellet fractions was determined by shaking portions of each with a small amount of sodium dithionite followed by examination with the hand spectroscope. There was strong absorption at $560 \mathrm{~m} \mu$ with the pellet, indicating the presence of cytochrome $b$, but no absorption bands were detected in the supernatant fluid.

\section{The effect of 2:4-dinitrophenol and azide}

2:4-Dinitrophenol or azide not only prevented the adaptation to various intermediates of the TCA cycle but also slowed their oxidation by whole adapted organisms (Table 2). A number of results indicated that the latter effect was not due to direct interference with respiration but with the mechanism for the transport of the substrates across the permeability barrier. Thus concentrations of 2:4dinitrophenol $(0.00036 \mathrm{M})$ or azide $(0.0036 \mathrm{M})$ which decreased the $\boldsymbol{Q}_{\mathrm{O}_{2}}$ value of L-malate, fumarate and succinate to $30-35 \%$ of the control values produced no inhibition of the oxidation of other compounds such as acetate and glucose. There was also very little effect of 2:4-dinitrophenol or azide on the initial rate of oxidation of L-malate and fumarate by cell-free extracts, prepared either by lysozyme treatment or by ultrasonic disintegration (Fig. 5).

\section{Attempts to show activation of substrates}

Both 2:4-dinitrophenol and azide are well known as uncouplers of oxidative phosphorylation and they may have a common point of attack on some endergonic process which is required for the mechanism of penetration. Since the energyrequiring process might be an activation of the substrate such as that proposed by Mitchell (1957) and Mitchell \& Moyle (1959) an attempt was made to detect the formation of reactive compounds by cell-free preparations by using hydroxylamine as trapping agent. Initially, ultrasonically-disrupted preparations of Corynebacterium erythrogenes which have been grown in the presence of succinate were used, with the dicarboxylic acids and acetate as substrates.

Dialysed extracts of ultrasonically disrupted bacteria which had been grown in the presence of succinate were incubated with cysteine, ATP, $\mathrm{CoA}, \mathrm{MgCl}_{2}$, hydroxylamine and substrate for $2 \mathrm{hr}$. at $30^{\circ}$. On the addition of ferric chloride reagent, coloured compounds were formed with each of the substrates, malate, fumarate, succinate and acetate. Deproteinization of the incubation mixture, followed by ethanol extraction and chromatography according to the method of Stadtman \& Barker (1950), showed that the compounds formed with acetate and succinate were the corresponding hydroxamates. The same method of extraction and chromatography applied to the incubation mixtures containing malate and fumarate failed to reveal compounds reacting as hydroxamates. In spite of this, the reaction of enzymic extracts with malate and fumarate was possibly related to the process of penetration, and further investigation was therefore made.

The effect of cofactors. The incubation conditions were as before. With fumarate the amount of coloured compound formed was independent of the presence of added CoA, ATP, cysteine and divalent metal ion. With L-malate, however, maximum colour development was obtained only in the complete system; omission of ATP or $\mathrm{CoA}$ and cysteine resulted in approximately $50 \%$ less absorption at $540 \mathrm{~m} \mu$ (Table 4). Magnesium or manganese jons were also needed for maximum 
activity with malate. Since both CoA and ATP were necessary for the formation of succinhydroxamate it is possible that the coloured malate compound is produced by two mechanisms, one of which requires CoA, ATP and divalent metal, and another which is independent of these compounds. The comparison of extracts from unadapted organisms with those from organisms grown in the presence of malate or succinate revealed no marked difference in activities.

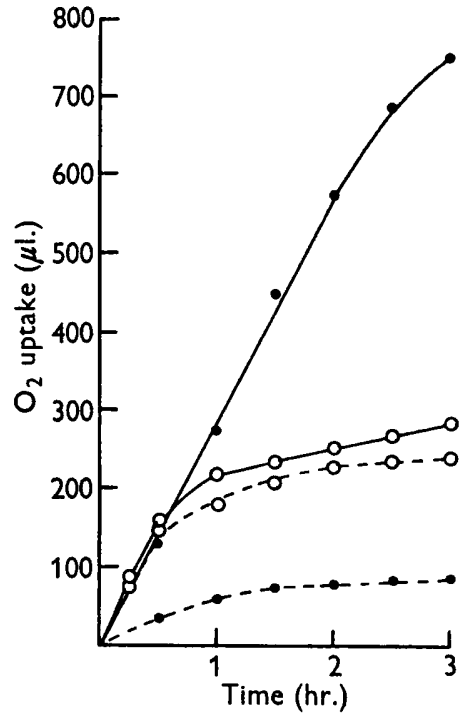

Fig. 5

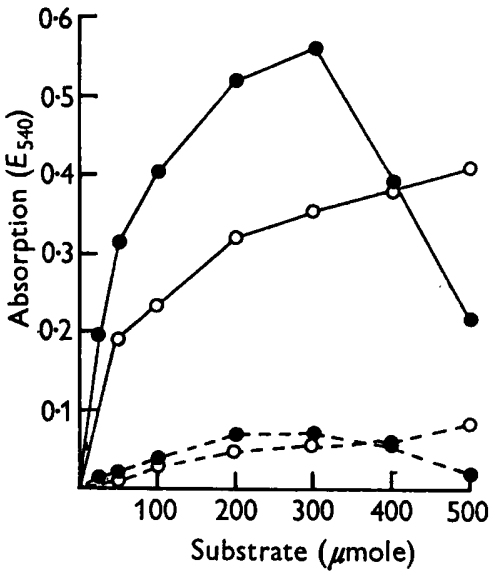

Fig. 6

Fig. 5. Effect of azide on the oxidation of malate by malate-grown Corynebacterium erythrogenes. Standard manometric conditions with L-malate $(20 \mu \mathrm{mole})$ added from side arm. Lysozyme (200 $\mu \mathrm{g}$.) present, $\bigcirc$; absent, O. Sodium azide $(0.0036 \mathrm{M})$ present, --- ; absent, - Temperature $25^{\circ}$. Corresponding endogenous $\mathrm{O}_{2}$ uptakes have been subtracted.

Fig. 6. Effect of substrate concentration on the reaction of dialysed, ultrasonic extracts of Corynebacterium erythrogenes, grown on basal medium alone, with hydroxylamine and L-malate or fumarate. Experimental conditions as in Table 4. Substrates: $O$, L-malate; O, fumarate. Boiled extracts, - - . Values have been corrected for the extinction at $540 \mathrm{~m} \mu$ in the absence of substrate.

The effect of fluoride. The formation of acyl hydroxamates in the absence of CoA and ATP was reported by Lipmann \& Tuttle (1950) and by Elliott (1956) and appears to be due to a non-specific reaction catalysed by lipase, especially when high concentrations of substrate are used. Potassium fluoride, which has been used to prevent this action of lipase (Lipmann \& Tuttle, 1950; Elliott, 1956), had no effect on the reaction of Corynebacterium erythrogenes ultrasonic preparations with malate and fumarate, either in the presence or the absence of CoA, ATP and cysteine.

The effect of concentration of extract, time of incubation and substrate concentration. The amounts of coloured compounds formed with malate and fumarate were proportional to the amount of ultrasonic preparation present (Table 5) and to the incubation times up to $2 \mathrm{hr}$. Colour produced in the reaction increased with increasing substrate concentration, though high concentrations of fumarate were inhibitory (Fig. 6). While the reaction of the preparations with fumarate and malate 
Table 4. The reaction of ultrasonic preparations of Corynebacterium erythrogenes with dicarboxylic acids in the presence of hydroxylamine

The complete incubation mixture contained : tris-HCl buffer (pH 7.4) $20 \mu$ mole; $\mathbf{M g C l}_{2}$, $10 \mu$ mole; cysteine, $6 \mu$ mole: ATP, $10 \mu$ mole; CoA, $0.05 \mu$ mole; hydroxylamine, $800 \mu$ mole; substrate, $300 \mu$ mole; dialysed ultrasonic preparation, equiv. 3-5 mg. protein; water to $2 \mathrm{ml}$. Incubation time $2 \mathrm{hr}$. at $30^{\circ}$. Absorption measured in $1 \mathrm{~cm}$. cuvettes after adding $1 \mathrm{ml}$. $\mathrm{FeCl}_{3}$ reagent and centrifuging.

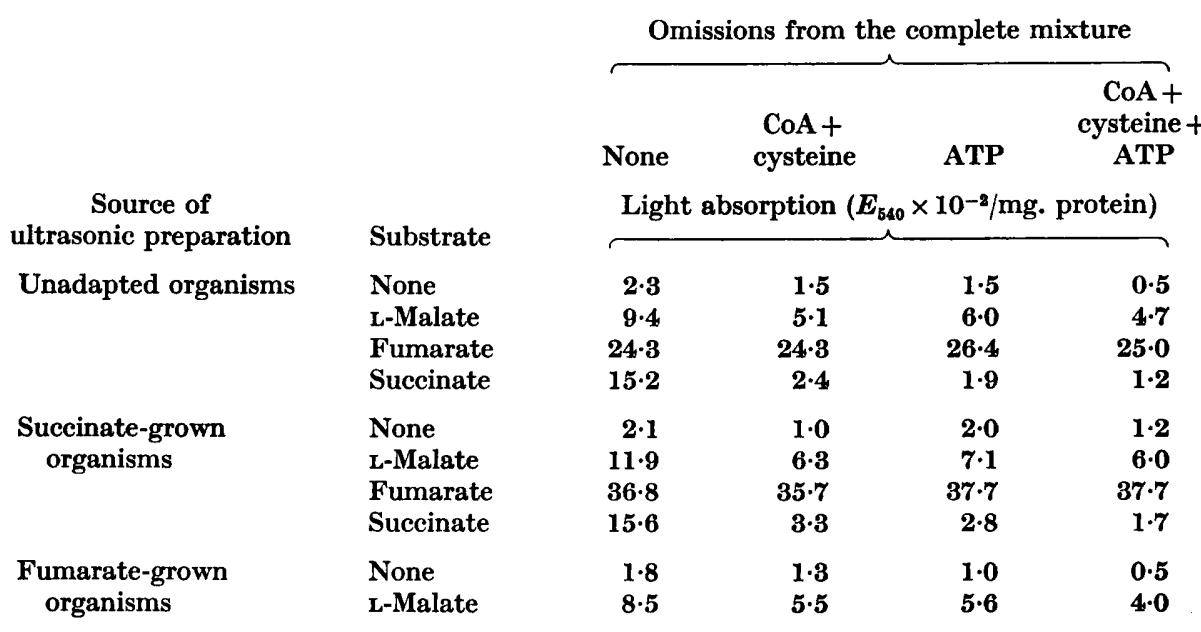

appeared to be enzymic, it was possible that the coloured compounds were not formed from these substances directly but from products of their further metabolism. Under the conditions of these experiments, namely incubation in open centrifuge tubes, malate and fumarate with all the additions except hydroxylamine gave rise to keto acids which were detected as the 2:4-dinitrophenylhydrazones. However, several observations made it unlikely that keto acid formation could account for the results. Thus no coloured compounds were formed on the addition

Table 5. Effect of protein concentration on the reaction of ultrasonic preparations of Corynebacterium erythrogenes with fumarate and hydroxylamine

Experimental details as in Table 4. Incubation time $2 \mathrm{hr}$. at $30^{\circ}$. The values of controls in the absence of substrate have been subtracted.

$$
\begin{array}{cc}
\begin{array}{c}
\text { Unheated } \\
\text { preparation }
\end{array} & \begin{array}{c}
\text { Heated } \\
\text { preparation* }
\end{array}
\end{array}
$$

$\begin{array}{ccc}\begin{array}{c}\text { Extract } \\ \text { (mg. protein) }\end{array} & \begin{array}{c}\text { Light absorption } \\ \left(E_{540} \times 10^{-2} / \text { mg. protein }\right)\end{array} \\ \text { None } & 0.10 & 0.10 \\ 0.54 & 0.18 & 0.09 \\ 1.07 & 0.25 & 0.09 \\ 2.14 & 0.37 & - \\ 3.20 & 0.47 & 0.06 \\ 4.28 & 0.57 & - \\ 5.35 & 0.61 & 0.06\end{array}$

* Enzymic activity of preparation destroyed by heating in water bath at $100^{\circ}$ for $10 \mathrm{~min}$. 
of ferric chloride reagent to the incubation mixture unless hydroxylamine was present, and anaerobic incubation greatly diminished the amount of keto compounds formed without significantly affecting the reaction between malate and hydroxylamine (Table 6). Also, dialysis of the ultrasonic preparation against water for $16 \mathrm{hr}$. instead of against $0.05 \mathrm{M}$-phosphate buffer ( $\mathrm{pH} 7 \cdot 0$ ) inactivated the mechanism responsible for the formation of the unknown compound but did not diminish keto acid formation.

Table 6. Effect of aerobic and anaerobic incubation of ultrasonic preparations of Corynebacterium erythrogenes on (a) the reaction with malate and hydroxylamine, (b) the formation of keto acids from L-malate

Aerobic incubation in $11 \times 1.5 \mathrm{~cm}$. centrifuge tubes. Anaerobic incubation in Thunberg tubes; gas phase $\mathrm{N}_{2}$; L-malate added from side arm. Incubation time $2 \mathrm{hr}$. at $30^{\circ}$. (a) Experimental details as in Table 4. Results expressed as $E_{540} \times 10^{-2} / \mathrm{mg}$. protein $/ 2 \mathrm{hr}$. (b) Experimental details as in Table 4 but hydroxylamine omitted. 2:4-Dinitrophenylhydrazones were prepared and amounts formed expressed as $\boldsymbol{E}_{\mathbf{4 4 0}} / \mathrm{mg}$. protein $/ \mathbf{2} \mathrm{hr}$.

\begin{tabular}{|c|c|c|c|c|c|c|c|c|c|}
\hline \multirow[b]{4}{*}{ Source of extract } & \multirow[b]{4}{*}{ Substrate } & \multicolumn{8}{|c|}{ Omissions from the complete incubation mixture } \\
\hline & & \multicolumn{4}{|c|}{ None } & \multicolumn{4}{|c|}{ CoA + ATP + cysteine } \\
\hline & & \multicolumn{2}{|c|}{ Aerobic } & \multicolumn{2}{|c|}{ Anaerobic } & \multicolumn{2}{|c|}{ Aerobic } & \multicolumn{2}{|c|}{ Anaerobic } \\
\hline & & (a) & (b) & $(a)$ & (b) & (a) & (b) & (a) & (b) \\
\hline $\begin{array}{l}\text { Fumarate-grown } \\
\text { organisms }\end{array}$ & $\begin{array}{l}\text { None } \\
\text { L-Malate }\end{array}$ & $\begin{array}{l}\mathbf{2 \cdot 3 3} \\
\mathbf{9 \cdot 0}\end{array}$ & $\begin{array}{l}0 \\
1 \cdot 34\end{array}$ & $\begin{array}{l}1.96 \\
9 \cdot 5\end{array}$ & $\begin{array}{l}0 \\
0 \cdot 26\end{array}$ & $\begin{array}{l}1 \cdot 28 \\
\mathbf{3} \cdot 98\end{array}$ & $\begin{array}{l}0 \\
1 \cdot 37\end{array}$ & $\begin{array}{l}1 \cdot 14 \\
4 \cdot 26\end{array}$ & $\begin{array}{l}0 \\
0 \cdot 19\end{array}$ \\
\hline $\begin{array}{l}\text { Fumarate-grown } \\
\text { organisms (ultra- } \\
\text { sonic preparation } \\
\text { dialysed against } \\
\text { water) }\end{array}$ & $\begin{array}{l}\text { None } \\
\text { L-Malate }\end{array}$ & $\begin{array}{l}1 \cdot 6 \\
2 \cdot 45\end{array}$ & $\begin{array}{l}0 \\
1 \cdot 3\end{array}$ & $\overline{-}$ & - & - & - & - & - \\
\hline
\end{tabular}

Localization of the enzymes responsible for the reactions of malate, fumarate and succinate with hydroxylamine

If the enzymes responsible for the activation of succinate and for the formation of the coloured compounds with fumarate and L-malate are concerned with the penetration of these substances into the bacteria, a differential distribution of them between cytoplasm and cell membrane might be anticipated. High-speed centrifugation $(105,000 \mathrm{~g})$ of the ultrasonic preparations caused the sedimentation of a dark red pellet, probably the small particle fraction corresponding to fragmented cell membrane (see Mitchell, 1959). The supernatant fluid from such centrifugation was yellow and, since it had malic dehydrogenase activity, it still contained material derived from the cell membrane. Nevertheless, if activating enzymes are situated in the membrane there might be relatively different amounts present in the two fractions. Using the same conditions as in Table 4 the supernatant fluid and pellet fractions were tested for their ability to form succinhydroxamate and the reactive compounds from malate and fumarate. The results showed that the supernatant fluid had greater activity per unit weight of protein than the pellet fraction. A similar experiment was carried out with the pellet and supernatant fluid fractions from organisms lysed with lysozyme. The supernatant fluid not only had greater enzymic 
activity than the pellet per unit weight of protein (Table 7) but also, since it contained more protein, greater total activity.

Table 7. Reaction of supernatant fluid and pellet fractions from lysed Corynebacterium erythrogenes with dicarboxylic acids and hydroxylamine

Experimental conditions as in Table 4. Incubation time $2 \mathrm{hr}$. at $30^{\circ}$.

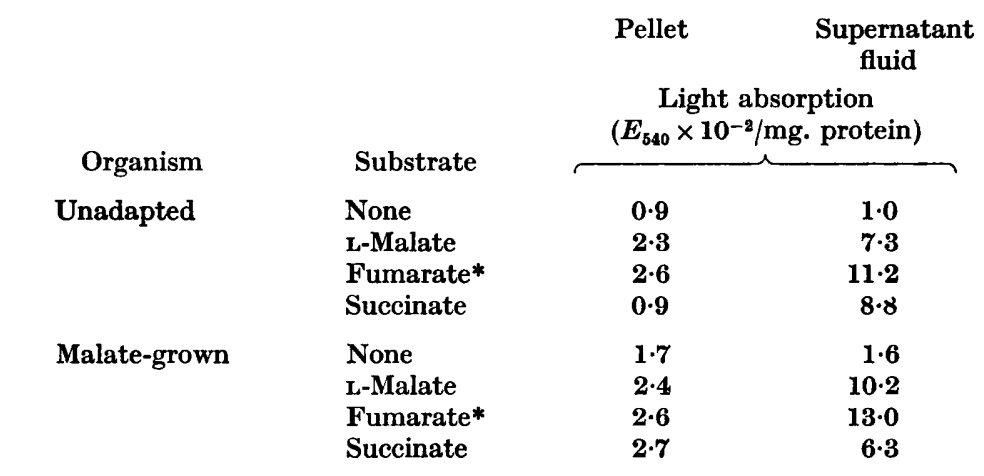

* CoA + cysteine + ATP were omitted from the tubes containing fumarate.

\section{DISCUSSION}

The adaptation to oxidize various TCA cycle intermediates which has been described for Corynebacterium erythrogenes is generally similar to the phenomenon observed with pseudomonads (Barrett et al. 1953; Kogut \& Podoski, 1953; Clarke \& Meadow, 1959), Azotobacter (Karlsson \& Barker, 1948; Stone \& Wilson, 1952) and Aerobacter aerogenes (Davis, 1956). Cell-free preparations from unadapted organisms contain many of the component enzymes of the cycle and since known inhibitors of induced enzyme formation (e.g. chloramphenicol, 2:4-dinitrophenol, azide, increase in temperature; Knox, 1953) all prevented the adaptive process it is reasonable to postulate a permeability barrier in these organisms which may be overcome by inducible transport mechanisms. However, the use of oxidation as an index of permeability, though necessary with metabolizable substrates, is an indirect measurement, and other explanations are not excluded. Some organisms contain distinct though functionally similar enzymes, for example malic dehydrogenase and isocitric dehydrogenase (Cohn, 1956; Markert \& Møller, 1959), and it might be possible for exogenous substrates to evoke special mechanisms for their oxidation.

The ability of lysozyme to cause an apparent increase in certain enzymic activities of Micrococcus lysodeikticus was noted by Penrose \& Quastel (1930). The primary action of lysozyme on Corynebacterium erythrogenes, as on other organisms, is probably the hydrolysis of the rigid cell wall (Salton, 1957), which when weakened sufficiently permits the rupture of the cell membrane and free access of a substrate to the cytoplasm. By balancing the internal osmotic pressure with a suitable impermeable substance it has been shown that protoplasts (Weibull, 1953) and spheroplasts retain many of the functions of the whole organism (McQuillen, 1956; Sistrom, 1958). This may explain why adaptation was still shown after lysozyme treatment of $C$. erythrogenes in the presence of sucrose. The result implies that the permeability barrier does not reside in the cell wall or in that component of the wall that is hydrolysed by lysozyme. In Bacillus megaterium (Storck \& Wachsman, 
1957; Weibull, Beckman \& Bergström, 1959) and Azotobacter vinelandii (Jose \& Wilson, 1959) there is a differential distribution of enzymic activities between the pellet and supernatant fluid fractions from lysozyme-treated organisms. While it is not certain that the pellet fraction obtained by centrifugation of organisms treated with lysozyme consisted of cytoplasmic membranes entirely uncontaminated with enzymes from the cytoplasm, nevertheless the absence of malic dehydrogenase and the cytochrome system from the supernatant fluid of lysed C. erythrogenes probably means that the permeability barrier and the inducible transport mechanism, at least for malate, is in the cytoplasmic membrane. This accords with the conclusions of Mitchell \& Moyle (1956), Davis (1956) and Rickenberg (1957) about the site of the permeability barrier.

The patterns of adaptation to TCA cycle intermediates in the organisms which have been examined in detail vary considerably; Clarke \& Meadow (1959) concluded that separate permeability mechanisms may exist for each substrate. The present finding that adaptation of Corynebacterium erythrogenes to L-malate makes the organism acquire permeability to succinate faster than does succinate itself, and that previous incubation with $\mathrm{D}$-malate enables rapid oxidation of all three dicarboxylic acids, suggests that these compounds have a common inducible factor involved in their transport. Alternatively, the results could be explained if $\mathrm{L}-$ and D-malate were better inducers of specific succinate and fumarate systems than these substrates themselves. The question whether or not each of these compounds has a specific transport process has some bearing on the mechanism of entry into the cells; at present little is known about this. The inhibitory effect of azide on the oxidation of succinate and acetate by Escherichia coli grown on these substrates (Goucher, Woodside \& Kocholaty, 1954) and of azide and 2:4-dinitrophenol on the oxidation of certain compounds by whole organisms but not by extracts of C. erythrogenes probably means that transport is an energy-requiring process, though if this is so it is curious that these two inhibitors had less effect when added after the substrate. This result may indicate that penetration is faster than oxidation, so that there is a temporary intracellular accumulation of substrate. Mitchell $(1957,1959)$ proposed that succinate, malate, fumarate and other compounds enter bacteria by group transfer reactions, and gave some evidence for the permeation of succinate into Micrococcus lysodeikticus as a succinyl compound (Mitchell \& Moyle, 1959). The enzymes in extracts of $C$. erythrogenes which appear to be responsible for the formation of hydroxamate compounds with malate and fumarate require further investigation, but their presence in both adapted (induced) and unadapted organisms implies that they do not form the inducible part of the transport mechanism. Their location mainly in the supernatant fluid after centrifugation of extracts does not necessarily mean that they do not function in penetration; vigorous shaking with glass beads is capable of releasing enzymic activity from particulate fractions (Linnane \& Still, 1955) and some release possibly occurs during ultrasonic disintegration and after lysis with lysozyme.

I am indebted to Professor D. D. Woods, F.R.S., for his advice and criticism. This work was aided by a grant to the Department from the Rockefeller Foundation. 


\section{REFERENCES}

Barrett, J. T., Larsen, A. D. \& Kallio, R. E. (1953). The nature of the adaptive lag of Pseudomonas fluorescens toward citrate. J. Bact. 65, 187.

BERG, P. (1956). Acyl adenylates: the interaction of adenosine triphosphate and Lmethionine. J. biol. Chem. 222, 1025.

Clarke, P. H. \& Meadow, P. M. (1959). Evidence for the occurrence of permeases for tricarboxylic acid cycle intermediates in Pseudomonas aeruginosa. J. gen. Microbiol. 20, 144 .

Coнn, D. V. (1956). The oxidation of malic acid by Micrococcus lysodeikticus. J. biol. Chem. 221, 413.

Dagley, S., Fewster, M. E. \& Happold, F. C. (1952). The bacterial oxidation of phenylacetic acid. J. Bact. 63, 327.

Davis, B. D. (1956). In Enzymes: Units of Biological Structure and Function, p. 509. Ed. O. Gaebler. New York: Academic Press Inc.

Euliotr, W. H. (1956). The enzymic activation of cholic acid by guinea-pig-liver microsomes. Biochem. J. 62, 427.

Friedemann, T. E. \& Haugen, G. E. (1943). Pyruvic acid. II. The determination of keto acids in blood and urine. J. biol. Chem. 147. 415 .

Goucher, C. R., Woodside, E. E. \& Kocholaty, W. (1954). The influence of dinitrophenol on the oxidation of acetate and succinate by Escherichia coli. J. Bact. 67, 593.

Herbert, D. (1955). In Methods in Enzymology, vol. 1, p. 753. Ed. S. P. Colowick and N. O. Kaplan. New York: Academic Press Inc.

Heyningen, W. E. van \& Gladstone, G. P. (1953). The neurotoxin of Shigella shigae. 3. The effect of iron on production of the toxin. Brit. J. exp. Path. 34, 221.

Hodgkiss, W., Liston, J., Goodwin, T. W. \& JAmikonN, M. (1954). The isolation and description of two marine microorganisms with special reference to their pigment production. J. gen. Microbiol. 11, 438 .

Jose, A. G. \& Wrlson, P. W. (1959). Metabolic activities of subcellular particles from Azotobacter vinelandii. Proc. nat. Acad. Sci., Wash. 45, 492.

Karlsson, J. L. \& Barker, H. A. (1948). Evidence against the occurrence of a tricarboxylic acid cycle in Azotobacter agilis. J. biol. Chem. 175, 913.

KaUfMan, S. (1955). In Methods in Enzymology, vol. 1, p. 714. Ed. S. P. Colowick and N. O. Kaplan. New York: Academic Press Inc.

KNOx, R. (1953). The effect of temperature on enzymic adaptation, growth and drug resistance. In Adaptation in Microorganisms. Symp. Soc. gen. Microbiol. 3, 184.

Kogut, M. \& PoDoskr, E. P. (1953). Oxidative pathways in a fluorescent Pseudomonas. Biochem. J. 55, 800.

Krebs, H. A., Gurin, S. \& Eggleston, L. V. (1952). The pathway of oxidation of acetate in baker's yeast. Biochem. J. 51, 614 .

Linnane, A. W. \& Still, J. L. (1955). The intracellular distribution of enzymes in Serratia marcescens. Biochim. biophys. Acta. 16, 305.

LipmanN, F. \& TutTle, L. C. (1950). Lipase-catalysed condensation of fatty acids with hydroxylamine. Biochim. biophys. Acta, 4, 301.

Lowry, O. H., Rosebrough, N. J., Farr, A. L. \& Randall, R. J. (1951). Protein measurement with the folin phenol reagent. J. biol. Chem. 193, 265.

Markert, C. L. \& Møller, F. (1959). Multiple forms of enzymes: Tissue, ontogenetic and species specific patterns. Proc. nat. Acad. Sci., Wash. 45, 753.

McQuillen, K. (1956). Capabilities of bacterial protoplasts. In Bacterial Anatomy. Symp. Soc. gen. Microbiol. 6, 127.

Mrtchell, P. (1949). A new technique for stirred aerated culture. Nature, Lond. 164, 846.

Mitchell, P. (1957). A general theory of membrane transport from studies of bacteria. Nature, Lond. 180, 134.

Mirchell, P. (1959). Structure and function in microorganisms. Biochem. Soc. Symp. 16, 73. 
Mrtcheld, P. \& Moyle, J. (1956). Osmotic function and structure in bacteria. In Bacterial Anatomy. Symp. Soc. gen. Microbiol. 6, 150.

Mitcheld, P. \& Moyle, J. (1959). Succinyl group-translocation through the plasma membrane of Micrococcus lysodeikticus. Biochem. J. 72, 21 P.

Monod, J., Conen-Bazire, G. \& CoHn, M. (1951). Sur la biosynthèse de la $\beta$-galactosidase (lactase) chez Escherichia coli. La spécificité de l'induction. Biochim. biophys. Acta, 7, 585.

Monod, J., Pappenheimer, A. M. \& Cohen-Bazire, G. (1952). La cinétique de la biosynthèse de la $\beta$-galactosidase chez Escherichia coli considérée comme fonction de la croissance. Biochim. biophys. Acta, 9, 648.

Moses, V. (1955). Tricarboxylic acid cycle reactions in the fungus Zygorrhynchus moelleri. J. gen. Microbiol. 13, 235.

NeIDHARDT, F. C. \& Magasanik, B. (1957). Effect of mixtures of substrates on the biosynthesis of inducible enzymes in Aerobacter aerogenes. J. Bact. 73, 260.

Penrose, M. \& Quastel, J. H. (1930). Cell structure and cell activity. Proc. roy. Soc. B, $107,168$.

Rickenberg, H. V. (1957). The site of galactoside-permease activity in Escherichia coli. Biochim. biophys. Acta, 25, 206.

Salton, M. R. J. (1957). The properties of lysozyme and its action on microorganisms. Bact. Rev. 21, 82.

Singer, T. P. \& Kearney, E. B. (1957). In Methods of Biochemical Analysis, vol. Iv, p. 307. Ed D. Glick. New York: Interscience Publishers Inc.

Sistrom, W. R. (1958). On the physical state of intracellularly accumulated substrates of $\beta$-galactosidase-permease of Escherichia coli. Biochim. biophys. Acta, 29, 579.

Spiegelman, S. \& DunN, R. (1947). Interactions between enzyme-forming systems during adaptation. J. gen. Physiol. 31, 153.

Stadtman, E. R. \& Barker, H. A. (1950). Fatty acid synthesis by enzyme preparations of Clostridium kluyveri. VI. Reactions of acyl phosphates. J. biol. Chem. 184, 769.

Stone, R. W. \& Wilson, P. W. (1952). Respiratory activity of cell-free extracts from azotobacter. J. Bact. 63, 605.

Storck, R. \& Wachsman, J. T. (1957). Enzyme localization in Bacillus megaterium. J. Bact. 73, 784.

WeIBULl, C. (1953). The isolation of protoplasts from Bacillus megaterium by controlled treatment with lysozyme. J. Bact. 66, 688.

Weibull, C., Beckman, H. \& Bergström, L. (1959). Localization of enzymes in Bacillus megaterium, strain M. J. gen. Microbiol. 20, 519. 